\title{
Will Employment Effect Gold Buying? An Indian Perspective
}

\author{
Swati Shrikant Godbole, Gita Sashidharan \\ Department of Finance and General Management, K. J. Somaiya Institute of Management Studies and Research, \\ Mumbai, India \\ Email: swatigodbole@somaiya.edu, gita@somaiya.edu
}

How to cite this paper: Godbole, S.S. and Sashidharan, G. (2019) Will Employment Effect Gold Buying? An Indian Perspective. Theoretical Economics Letters, 9, 1225-1234. https://doi.org/10.4236/tel.2019.95079

Received: February 15, 2019

Accepted: May 5, 2019

Published: May 8, 2019

Copyright (c) 2019 by author(s) and Scientific Research Publishing Inc. This work is licensed under the Creative Commons Attribution International License (CC BY 4.0).

http://creativecommons.org/licenses/by/4.0/

\begin{abstract}
In India, the uniqueness of gold has been widely discussed since ages. The Indian Government has led several initiatives to curb gold consumption in order to restrict its impact on trade deficit and forex reserves. However, their attempts have been quite futile. In light of the above and combined with the high demand for gold in the form of jewelry, this research paper was crafted. This paper attempts to study the factors of gold buying of retail consumers and also analyze the impact of reference groups on gold buying. The central focus of the study being retail consumers, data were collected from a sample of 600 retail consumers. Several factors were identified through factor analysis. The validity and reliability of factor analysis was confirmed by KMO (0.903) and Bartlet tests (Sig. 0.000). ANOVA was performed to ascertain the impact of reference groups/employment function on the identified factors. The ANOVA results indicated that the proposed hypothesis was observed to be statistically significant for some of the identified factors. Results of Tukey Post Hoc Test highlighted pairing of other function (retired) of employment with either Marketing or IT giving statistically significant different means. For several years, gold has been an area of secondary research both in the foreign and Indian context. However in the light of gold buying's (Jewelry) negative impact on India's trade deficit and various initiatives of the government, this research has relevance in the Indian context. More so since in the existing era, India is a growing economy and globalization and technology has made it easy and possible to buy or invest in the paper form of gold instead of the physical form.
\end{abstract}

\section{Keywords}

India, Gold Buying, Reference Group-Employment Function, ANOVA, Tukey Post Hoc Test 


\section{Introduction}

Consumer Behaviour has been an area of research interest since aeons. The rapid pace of changes occurring around consumer behaviour has contributed prominently to studies in this area. Consumer Behaviour as defined by many authors is the behaviour of consumers influenced by the wants, needs, personality, taste, philosophy, work function, work culture, thought process etc. [1]. Past studies of various authors have classified these factors to be either demographic (Income, gender, marital status, age etc.), geographical, psychological (motivation, Beliefs, Perception) or socio-cultural [2] [3] [4].

Several prior researchers of consumer behaviour and consumer buying decision had attributed seven significant factors such as economical, functional, personal, marketing mix, psychological, cultural and social to impact the behaviour of consumers and their buying decision. Social factors were classified as reference groups, family and social status. A similar view was prevalent for consumption of luxury products [5] [6] [7].

Significant among the several consumer behaviour theories is the socio-cultural theory propounded by Thorsten Veblen [8] that emphasized the influence of culture, social class, reference groups, family members and individual experiences on the buyer behaviour.

The Howard-Sheth consumer behaviour model propounds that informational cues emerge from a buyer's social environment to influence consumers buying decision. Social environment includes family, reference groups and social class as a key determinant in consumers' buying decision [9].

Quite a number of studies allude to the influence of "Reference Groups" on the buying decisions of individuals. Reference group is observed to be a group in which an individual or another group can be compared. Reference groups offer both benchmarks and contrasts required for comparison and evaluation for the group as well as personal traits. It has been hypothesized that individuals compare themselves with reference groups of people who occupy the social role to which the individual aspires [10]. Considerable research has been conducted on the application of reference groups in studies covering farmers, scientists, alcoholics, physicians, opinion leaders, consumers, auto-owners, students and housewives, cosmetic users, voters etc [11] [12] [13] [14] [15]. Several studies have also investigated reference group influences on product choice, brand choice, perceived risk etc [16]. Further, advertisers have used reference group concepts to persuade and influence a favorable consumer disposition. Reference groups are predominantly used by marketers in their communications to influence consumer behaviour and effect pressure for conformity to group norms [17].

Consumer buying behavior in general and with respect to consumer durable products has always been researched for developing marketing strategies. There has been significant research on the influence of reference groups/social class on the buying patterns for various generic products and consumer durables globally [10]. In comparison, gold is a unique commodity as it does not carry any credit 
risk besides being a non-essential commodity. Gold as a commodity has been predominantly researched globally from an institutional investment perspective either as a hedge or credit risk instrument or due to its trade-off attribute in declining markets. In India, although gold does have significance from an industrial and trade-off perspective; it is largely consumed as an item of jewelry (World Gold Council Report 2009-10 to 2016-17 [18]). Very little attempts have been made in India to research from a retail consumer's perspective the role of savings, price of gold, quest for real income, impact of lifestyle, herd behavior on gold demand [19] [20]. These researches were restricted to either small districts of Tamil Nadu or covered only a small sample from Chennai, Punjab etc. [21]. One fifth of the annual global gold consumption is accounted for by India. India is the second largest country in the world for gold consumption and gold's impact on $\mathrm{CAD}$ and an indirect impact on Indian currency are vital reasons for a retail consumer/common man to read and research on gold/gold consumption [22].

\section{Literature Review}

A systematic review of prior literature on the significance of understanding factors that influenced consumers' buying decision was performed.

It has been professed in a study on "Impact of Celebrity Endorsement on Consumer Buying Behaviour-A case study of Durable Products in District Udhampur, J \& K" by Rakesh Kumar and Narinder Singh [23] that Internal factors (classified as Individual's own motivation, personality, perception, learning attitude, past experience etc.) and External factors (classified as Opinions/ideas of friends, relatives, family members', reference groups, company's marketing efforts etc.) influenced the buying behaviour of the consumer. The study opined that celebrity endorsements significantly affected the buying behaviour of the consumers and the impact varied with different age groups due to their differences in perception of the celebrity [23].

The study conducted by Hundal [24] highlighted on the consumer-centrism attribute of every business; where the purchase decisions of consumers were affected by variables that included type of family, income level, occupation, educational level, status and the like.

An analysis conducted by Acebron et al. [25] on the impact of previous experience of consumers using SEM" observed the direct impact of personal habits and previous experience on the consumers' purchase decision.

Income level, family size, occupation, and education labeled as demographic factors were noted to have influenced decision making in a study by N.Geeta and Dr.M.Ramesh [26].

An analysis by "Mint" observed that the possession of gold was seen to be a universal phenomenon across all income classes [27]. A survey [27] amongst 61,000 households in India observed that one of every two households purchased gold in the last five years and $87 \%$ of households owned some amount of gold. (2016, Mint). Noteworthy of the many observations was the one on the buying 
behaviour of gold. It was seen that purchase of gold during weddings was common for significant sections of the household; however majority of households were observed to have purchased gold for other "Social Purposes" such as gifts, personal use, to offer for worship, for festivities or to enhance social status. The survey revealed that in India, the low penetration of insurance products, inadequate financial knowledge and social security made gold buying more a necessity than luxury.

Robert A Nagy \& Robert W. Obenberger [28] in their study on "Factors influencing Individual Investor's behaviour" expressed the view that recommendations of friends, peers, advisors or brokers are largely overlooked by Investor's while selecting stocks.

A study on "The impact of socio-economic profile on investment pattern of salaried and business People" observed no correlation between occupation, annual income, annual savings and frequency of making an investment. It also revealed no significant difference in the investment patterns of the Government/ Public/Private Class of salaried investors as well as business, retail and service class investors. However, it was noted that income level influenced investment decisions [29].

A review of behavioural finance literature noted the significant role of income level and occupation on the selection of investment avenues. Factors like security, periodic returns, tax benefit, secure future was seen to play a vital role in the decision making process. Risk taking was observed to be more predominant in male investors as compared to female investors [30].

It has been examined by Manish Sitlani, Geeta Sharma \& Bhoomi Sitlani [31] that investors do not exhibit rational behaviour in their investment choices; they are influenced more by demographic factors like age, gender, income level etc.

A study on "Investor's attitude towards investment and risk with regard to Information Technology professionals from the city of Coimbatore" associated socio-economic factors such as age, gender, education level, social status, nature of family, nature of job etc. to impact the respondents attitude towards investment and risk [32].

P. Arulmurugan, K. Balanagaguruthan and Mirudhubashini [21] conducted a study in Tamilnadu to ascertain the investment criteria of professors. They accented the influence of demographic factors (age, gender, marital status etc.), family characteristics (stage of family life cycle, monthly family income etc.) and other factors like safety, liquidity, traditional value, risk and returns on the investment behaviour of the professors.

In summary, a review of literature reveal that besides demographics a predominant factor influencing purchase decisions are socio-cultural factors such as peer group-employment, friends, family, and advisors.

\section{Objective}

Based on the literature review and the identified gaps there are two objectives of this study. Firstly, to identify if employment function has statistically significant difference on various identified factors of gold buying. Secondly, to identify which pairs of group have statistically different means than the other group. 


\section{Research Methodology}

\subsection{Variables of the Study}

Employment function was defined to mean a function where an individual works i.e. the department in which an individual works. The current sample was classified into 6 groups-Finance, Marketing, HR and RD, IT, Operations and admin and the retired.

\subsection{Data}

Today, there are a variety of instruments available for people to buy or invest in gold. The consumer need not necessarily buy physical gold. Gold buying has become easier with the introduction of the Paper form of gold that gives varied benefits such as safety, no storage space, ease in liquidation to name a few. Against this back drop, data was collected from contemporary metro cities that are different from tier 1 cities due to its infrastructural, technological and employment advancements. The metro cities selected for this study were Mumbai, Delhi, Calcutta, Bangalore, Ahmedabad, Chennai and Hyderabad. These cities were favored since they are ranked as the top six metro cities in India as well as the most populous cities in India. $\left[{ }^{*}\right]$ Further, the levels of awareness about paper form of gold were evident in these metros (World Gold Council Report 2009-10 to 2016-17 [18]). Data collection was contained only to these six top metros cities due to time constraints too.

*[Source: https://www.census2011.co.in/city.php] [33];

*[Source: https://en.wikipedia.org/wiki/list_of_cities_India_by_population] [34]

The data was collected through an instrument from a sample of 600 respondents spread across India (from the above mentioned cities). The initial process of factor analysis resulted into eleven factors (Table 1). The factors and their related details were as follows:

\subsection{Tables}

Table 1. Factor analysis results.

\begin{tabular}{cccc}
\hline Factors & Eigen value & \% of Variance Explained & \% of Cumulative Variance \\
\hline Purchase Motivation & 10.381 & 24.716 & 24.716 \\
Ease of Purchase & 3.352 & 7.982 & 32.698 \\
Perceived Purchase Risk & 2.448 & 5.829 & 38.527 \\
Comparative Perception & 1.816 & 4.325 & 42.852 \\
Inhibitor for purchase & 1.691 & 4.026 & 46.877 \\
Perceived Reasons & 1.479 & 3.521 & 50.399 \\
Investment Rationale & 1.237 & 2.944 & 53.343 \\
Purchase Intentions & 1.186 & 2.823 & 56.166 \\
Perceived Benefits & 1.167 & 2.778 & 58.944 \\
Perceived Utility & 1.089 & 2.592 & 61.536 \\
Pricing & 1.026 & 2.444 & 63.980 \\
\hline
\end{tabular}


The identified factors covered items such as drivers for consumers' motivation, consumers' perception with respect to risk, their perceived reaction to market events/changes, perceived opinions and reasoning behind gold buying. Our study attempted to understand the significance of employment function on identified factors by performing "One way ANOVA" and "Tukey post Hoc test" to meet the objectives.

\section{Hypothesis}

Ho: There will be no statistically significant difference of employment function on the identified factors of gold buying.

H1: There will be statistically significant difference of employment function on the identified factors of gold buying.

\section{Data Analysis and Results}

Veblenian model mentioned that a human being is primarily a social animal and that the wants and behaviour of a human is impacted largely by the group to which he belongs as a member or otherwise. The model also stated that the buyer behaviour gets affected by the culture, sub culture, social classes, references and his or her family. The same viewpoint has been expressed under the Howard-Sheth model. The results of our study also exhibited similar aspects on examining the first research hypothesis (Table 2). It was observed that there was statistically significant difference due to employment function on Purchase Motivation, Ease of Purchase, Perceived Purchase Risk, Inhibitor for purchase, Investment Rationale, Purchase Intentions and Perceived Utility factors of gold buying.

Table 2. ANOVA results.

\begin{tabular}{ccc}
\hline Factors & Significant Value $(\mathrm{p}<0.05)$ & $\begin{array}{c}\text { Alternative Hypothesis } \\
\text { Accepted/Rejected }\end{array}$ \\
\hline Purchase Motivation & 0.002 & Accepted \\
Ease of Purchase & 0.077 & Rejected \\
Perceived Purchase Risk & 0.008 & Accepted \\
Comparative Perception & 0.215 & Rejected \\
Inhibitor for purchase & 0.002 & Accepted \\
Perceived Reasons & 0.258 & Rejected \\
Investment Rationale & 0.000 & Accepted \\
Purchase Intentions & 0.000 & Accepted \\
Perceived Benefits & 0.443 & Rejected \\
Perceived Utility & 0.019 & Accepted \\
Pricing & 0.315 & Rejected
\end{tabular}

Since, statistically significant difference was observed due to employment 
function on few factors of gold buying, "Tukey Post Hoc test" was carried out to evaluate which pairs of groups have statistically significant different means. The results indicated that for Investment Rational and Purchase intention factors, many pairs had statistically significant different means from each other, whereas Inhibitor for Purchase and Perceived Utility factors had only one pair (Marketing and Retired) with statistically significant different means. The result of the same is listed below (Table 3).

Table 3. Tukey post HOC test.

\begin{tabular}{ccc}
\hline Factors & Pairs & Significance \\
\hline \multirow{2}{*}{ Purchase Motivation } & Marketing and Retired & 0.001 \\
& IT and Retired & 0.013 \\
Perceived Purchase Risk & Marketing and Retired & 0.015 \\
& IT and Retired & 0.043 \\
Inhibitor for purchase & Marketing and retired & 0.002 \\
& IT and Retired & 0.006 \\
Investment Rationale & Finance and Marketing & 0.005 \\
& Marketing and HR & 0.005 \\
& Marketing and Retired & 0.000 \\
& IT and Retired & 0.014 \\
& Operations and Retired & 0.036 \\
Perceived Utility & Finance and Retired & 0.000 \\
& Marketing and Retired & 0.000 \\
& HR and Retired & 0.000 \\
& IT and Retired & 0.000 \\
& Operations and Retired & 0.006 \\
& Marketing and Retired & 0.001 \\
\hline
\end{tabular}

\section{Conclusions and Future Scope}

Previous research on consumer durable goods had identified demographic, social factors etc. to influence consumer buying decision. Apart from demographic and social factors, motives/intentions [35] general perceptions, psychological and sociological needs too were observed to impact the buying decisions of retail consumers. Celebrity endorsement also has been seen to impact the decision making of consumers [23] [36]. The renowned Howard-Sheth model also had identified Motives, Satisfactions, Intentions, Perceptions, Price, Quality etc. to be major factors that influenced buying decisions (Theory of buyer behaviour). Results of the factor analysis of our research indicated identical factors for gold buying.

The focus of this study was to analyze the impact of reference group/employment function on the factors of gold buying. The Howard-Sheth consumer behaviour model ascribed social factors comprising of family, reference groups and social 
class to influence consumers' buying decision. Our study revealed that for "gold" too one of the social factors, namely employment function had a similar impact.

In spite of gold being observed to be a non-essential but costly commodity, a similar set of factors were observed to impact gold buying decision. Employment function/reference groups were observed to be impacting Purchase motivation, Purchase intentions, perceived utility and perceived risk factors of gold buying. Marketing and IT functions were observed to be the only functions showing greater impact (difference in means under pairwise analysis) than the rest of the functions. The observations of our study reveal a wider scope for further research selecting a larger sample covering tier 1, tier 2 cities to establish if similar results will be observed. Further, our present research paper has only addressed the employment function irrespective of the city of employment. There exists future scope to study the combined impact of employment function and city of employment on gold buying. Additionally, there is scope to study the sole impact of demographics such as age, gender, income, place of stay, and the joint impact of income vis-à-vis employment on gold buying.

\section{Conflicts of Interest}

The authors declare no conflicts of interest regarding the publication of this paper.

\section{References}

[1] Stallworth, P. (2008) Consumer Behaviour and Marketing Strategic. 9.

[2] Wiedermann, K., Hennigs, N. and Siebels, A. (2007) Measuring Luxury Consumer Perception: A Cross-Cultural Framework. Academy of Marketing Science Review, 7, 1-20.

[3] Winer, R. (2009) New Communications Approaches in Marketing; Issues and Research Directions. Journal of Interactive Marketing, 23, 108-117. https://doi.org/10.1016/j.intmar.2009.02.004

[4] Hoyer, W.D., McInnis, D.J. and Pieters, R. (2012) Consumer Behaviour. 6th Edition.

[5] Michael, R. (1975) Education, Income, and Human Behavior. 233-252. http://www.nber.org/books/just75-1

[6] Waheed, A., Mahasan, S.S. and Sandhu, M.A. (2014) Factors That Affects Consumer Buying Behaviour: An Analysis of Some Selected Factors. Middle East Journal of Scientific Research, 19, 636-641.

[7] Kumar, R. (2014) Impact of Demographic Factors on Consumer Behaviour-A Consumer Behaviour Survey in Himachal Pradesh. Global Journal of Enterprise Information System, 6, 35-47.

[8] Thorstein, V. (1899) The Theory of the Leisure Class.

[9] Sheth, J.N. and Howard, J.A. (1969) The Theory of Buyer Behaviour. Wiley, Hoboken.

[10] Merton, R.K. and Rossi, A.S. (1968) Contributions to the Theory of Reference Group Behaviour. The Free Press, New York.

[11] Herbert, H. and Singer, E. (1968) Readings in Reference Group Theory and Re- 
search. The Free Press, New York.

[12] Louis, K. (1955) Occupational Controls among Steel Distributors. American Journal of Sociology, 56, 203-212.

[13] Coleman, J.S., Katz, E. and Menzel, H. (1966) Medical Innovation: A Diffusion Study. Bobbs Merrill, Indianapolis.

[14] Moschis, G.P. (1976) Social Comparison and Informal Group Influence. Journal of Marketing Research, 13, 237-244. https://doi.org/10.1177/002224377601300304

[15] Whan, P.C. and Lessig, V.P. (1977) Students and Housewives: Differences in Susceptibility to Reference Group Influences. Journal of Consumer Research, 4, 102-110. https://doi.org/10.1086/208685

[16] Witt, R.E. and Bruce, G.D. (1970) Purchase Decisions and Group Influence. Journal of Marketing Research, 7, 533-535. https://doi.org/10.1177/002224377000700417

[17] Philip, K. (1970) Marketing Management: Analysis, Planning and Control. Prentice Hall, Englewood Cliffs.

[18] World Gold Council Report 2009-10 to 2016-17.

[19] Hundal, B.S., Grover, S. and Bhatia, J.K. (2013) Herd Behaviour and Gold Investment: A Perpetual Study of Retail Investors. IOSR Journal of Business and Management, 15, 63-69. https://doi.org/10.9790/487X-1546369

[20] Sujatha, V. and Kumaresan, S. (2013) Influence of Lifestyle Perception on Gold Purchase Decisions. Global Research Analysis, 2, 27-28.

[21] Arulmurugan, P., Balanagaguruthan, K. and Mirudhubashini (2013) A Study on Investment Behaviour of Professors towards Gold with Special Reference to Tamilnadu State. International Journal of Scientific Research, 2, 233-237.

[22] Business Standard 24th May 2016.

[23] Kumar, R. and Singh, N. (2015) Impact of Celebrity Endorsement on Consumer Buying Behaviour-A Case Study of Durable Products in District Udhampur, J \& K. Asian Journal of Multidisciplinary Studies, 3, 201-208.

[24] Hundal, B.S. (2008) Significant Considerations in the Purchase of Consumer Durables. The ICFAI Journal of Marketing Management, 7, 6-16.

[25] Acebron, L.B., Mangin, J.P.L. and Dopico, D.C. (2000) A Proposal of the Buying Model for Fresh Food Products: The Case of Fresh Mussels. Journal of International Food and Agribusiness Marketing, 11, 75-96. https://doi.org/10.1300/J047v11n03_04

[26] Geeta, N. and Ramesh, M. (2012) A Study on Relevance of Demographic Factors in Investment Decisions. Perspectives of Innovations, Economics \& Business, 10, 14-27. https://doi.org/10.15208/pieb.2012.02

[27] Household Survey on India's Citizen Environment and Consumer Economy (ICE $360^{\circ}$ Survey 2016).

[28] Nagy, R.A. and Obenberger, R.W. (1994) Factors Influencing Individual Investor's Behaviour. Finance Analysts Journal, 50, 63-68.

https://doi.org/10.2469/faj.v50.n4.63

[29] Ramanujam, V. and Chitradevi, K. (2012) A Study on Impact of Socio-Economic Profile on Investment Pattern of Salaried and Business People in Coimbatore City. International Journal of Management \& Information Technology, 2, 67-77. http://www.themoneyquest.com/2008/11/gold-as-alternative-asset-class-5.html https://doi.org/10.24297/ijmit.v2i1.1412

[30] Harikanth, D. and Pragathi, B. (2012) Role of Behavioural Finance in Investment 
Decision Making-A Study on Select Districts of Andra Pradesh, India. International Journal in Multidisciplinary and Academic Research, 1, 1-15.

[31] Sitlani, M., Sharma, G. and Sitlani, B. (2011) Investment Choices of Occupants of Financial Services Industry: A Demographic Study. The IUP Journal of Behavioral Finance, 8, 29-40.

[32] Sasirekha, P.S. and Jerinabi, U. (2015) Investor's Attitude towards Investment and Risk. Indian Journal of Applied Research, 5, 359-361.

[33] https://www.census2011.co.in/city.php

[34] https://en.wikipedia.org/wiki/list_of_cities_India_by_population

[35] Bagozzi, R.P. and Utpal, D. (1999) Goal Setting and Striving Consumer Behaviour. Journal of Marketing, 63, 19-20.

[36] Baso, J. and Reginald, E. (2014) Buying Behaviour of Rowan University Students. University Press. 